\title{
EL PERFIL DE COMPETENCIA PROFESIONAL EN LA FORMACIÓN DEL CIRUJANO GENERAL
}

\author{
HÉCTOR CANTELE PRIETO
}

Hace aproximadamente 40 años, era común escuchar en los pasillos de los hospitales universitarios de nuestro país la necesidad de evolucionar en los cambios que se venían sucediendo a nivel mundial con relación a la duración del postgrado de cirugía general.

Desde entonces, la Facultad de Medicina de la Universidad Central de Venezuela mostró interés en la propuesta, sin embargo, esta nunca se llevó a cabo.

Es a partir del año 2017 cuando iniciamos un programa acorde con los avances que imponía la nueva tecnología, desde el Departamento de Cirugía del Hospital Universitario de Caracas, avalado por la Coordinación de Estudios de Postgrado-UCV.

En este contexto y acorde a la vanguardia del conocimiento quirúrgico, vinculado a la globalización en el mundo, nos propusimos desarrollar el Proyecto de Reforma Curricular del Programa de Postgrado en Cirugía General, con el objeto de colocarlo al nivel de los estándares internacionales.

Este proyecto se fundamentó inicialmente en tres grandes pilares:

1. Adecuar los años de estudios del programa de cirugía general con lo establecido, mundialmente: de tres años a cuatro años.

2. Mejorar las posibilidades de aprendizaje de los aspirantes del programa prolongando el mismo a cuatro años en su formación académica.

3. Adquirir nuevos conocimientos acerca del abordaje clínico del paciente, a través de los avances en medicina.

El trabajo finalizado, fue presentado al Consejo Central de Postgrado de la UCV el 14 de diciembre de 2020, siendo aprobado por unanimidad.

Una vez logrado este objetivo, falta adecuarlo a los estándares educativos internacionales basados en el Perfil de Competencia Profesional.

El Perfil de Competencia Profesional es un estilo de educación médica que pretende establecer la orientación educativa necesaria para dar respuesta a las necesidades de la población y de esta forma adecuarse a la responsabilidad social que le corresponde.

Debemos construir el Perfil Profesional del Cirujano General que represente a nuestra sociedad, para desarrollar programas fundamentados en Educación Médica Basada en Competencia que comprende la adquisición de la competencia profesional (habilidades-destrezas, actitudes, así como los conocimientos) y las estrategias de aprendizaje y evaluación.

Durante los últimos años, la educación era transmitida por el educador como fuente experta del conocimiento de manera vertical, fundamentada en la transmisión de contenidos, siendo evaluados estos en tareas y exámenes.

Por otra parte, la Organización de las Naciones Unidas para la Educación, la Ciencia y la Cultura (UNESCO) se ha planteado como uno de sus objetivos propiciar el aprendizaje permanente y la construcción de la competencia profesionales adecuadas para contribuir al desarrollo cultural, social y económico de la sociedad.

De allí la importancia de establecer el Perfil de Competenia Profesional para la formación del cirujano general y establecer como reto académico, el superar la manera de enseñanza que hasta hoy se ha venido utilizando en las diferentes escuelas de postgrado de cirugía en las universidades del país y transformarla en aquella que permita el desarrollo de la competencia profesional (habilidades-destrezas y actitudes, así como los conocimientos), la organización de estrategias de aprendizajes y métodos de evaluación, la creación de criterios de desempeño para cada dominio de competencia y haciendo énfasis en el aprendizaje permanente para su evaluación formativa.

De manera que hemos ido avanzando hacia la educación necesaria que imponen los cánones internacionales. Este fin último, en el área de los programas de educación para la formación del cirujano general en nuestras aulas y hospitales universitarios, será culminado, en el momento que los programas sean presentados bajo la modalidad de un adecuado Perfil de Competencia Profesional que de respuesta a las necesidades del país con el nuevo modelo de enseñanza.

Cirujano General, Clínica Santa Sofía. Jefe Servicio Cirugía IV Hospital Universitario de Caracas

DOI: $\underline{10.48104 / R V C .2021 .74 .1 .6}$ 